Article

\title{
Free Software Beyond Radical Politics: Negotiations of Creative and Craft Autonomy in Digital Visual Media Production
}

\author{
Julia Velkova \\ Department of Media and Communication Studies, Södertörn University, 14189 Huddinge, Sweden; \\ E-Mail: julia.velkova@sh.se
}

Submitted: 16 January 2016 | Accepted: 27 February 2016 | Published: 11 August 2016

\begin{abstract}
Free software development and the technological practices of hackers have been broadly recognised as fundamental for the formation of political cultures that foster democracy in the digital mediascape. This article explores the role of free software in the practices of digital artists, animators and technicians who work in various roles for the contemporary digital visual media industries. Rather than discussing it as a model of organising work, the study conceives free software as a production tool and shows how it becomes a locus of politics about finding material security in flexible capitalism. This politics is ultimately contradictory in that it extends creative and craft autonomy of digital artists but does not mobilise a critical project. Instead, it nurtures further precarious labour. Empirically, the article draws on ethnographically collected material from the media practices of digital artists and programmers who engage with two popular free software production tools, Blender and Synfig.
\end{abstract}

\section{Keywords}

Blender; craft autonomy; F/OSS; media tools; material politics; media industries; open source software; post-Fordism; Synfig

\section{Issue}

This article is part of the issue "Political Agency in the Digital Age: Media, Participation and Democracy", edited by Anne Kaun (Södertörn University, Sweden), Maria Kyriakidou (University of East Anglia, UK) and Julie Uldam (Roskilde University, Denmark).

(C) 2016 by the author; licensee Cogitatio (Lisbon, Portugal). This article is licensed under a Creative Commons Attribution 4.0 International License (CC BY).

\section{Introduction}

Media practices, such as free and open source software development, and the technological experiments of hackers have been broadly recognised as fundamental for the formation of political cultures that foster democracy in the digital mediascape. Their relevance for political agency today is expressed through the ability of actors who take part in these practices to reconfigure 'the material politics of cultural action' (Coleman, 2013, p. 185), primarily through introducing new 'entities' into the world (Söderberg, 2011, p. 23), and by making them public (Kelty, 2008). These entities can range from material objects that take the form of open hardware, such as self-made 3D printers (Söderberg, 2014), through writing an independent operating system (Coleman, 2013; Kelty, 2008), creating alternative institutions for intellectual property rights management, to experimenting with digital aesthetics and critical art projects (Morgan, 2013). In all these cases, politics is practised primarily through creatively engaging with building, modifying and maintaining technological equipment, an activity that resembles both public demonstrations of technical expertise and a way of arguing about technology with and through it (Kelty, 2008; Kubitschko, 2015).

Occasionally, the public entities and institutions that are brought to the world can inspire broader social groups to repurpose them for other goals and embed them in other practices, imbuing them with other meaning. Such cultural 'modulations' (Kelty, 2008, p. 242ff) of free software often represent forms of criticism, such as in the case of Indymedia, to make a case for alternative journalism (Atton, 2007; Lievrouw, 
2011), its use by the open data movement (Baack, 2015), its use for creating alternative social media networks (Gehl, 2015) and the emergence of the Creative Commons licences for open cultural production (Coleman, 2013, p. 197ff). Free software also plays an important role among artistic minorities as a way to develop criticism of dominant regimes of ownership over digital 'materials', i.e. software used to make visual media (Morgan, 2013).

Despite the richness and importance of these studies, one of their limitations has been their focus on the uses of free software predominantly for political activism by social movements and creative minorities. However, free and open source software has also come to be increasingly integrated in the practices of corporate technological manufacturers like IBM, Google and Hollywood computer graphics giants Disney and Pixar. With regards to these developments, Kelty (2013) suggests that corporate use of free software threatens to make its critical potential 'sterile' by being equally easily put to use to mobilise counter-critical power that strengthens monopolies rather than to criticise them. At individual level, free software could also be used instrumentally for technical career advancement: 'for a great many software developers, toiling as they do in the richer veins of freelance precarity, it meant not having to rebuild the same damn thing over and over again with every upward career move' (Kelty, 2013). Kelty concludes that 'As open source becomes an instrumentalized kind of politics, the possibility of new beginnings fades'. Thus, the critical potential offered by free software seems to simultaneously flourish among activists, and get neutralised by its use in the media industries, converting it into a motor for new models of value creation (Barron, 2013).

This article seeks to broaden the scope of knowledge about the role of free software in the politics of digital media production by discussing its relevance for other actors, beyond activists, hackers or large media corporations. In particular it explores its value, use and development among computer graphics artists, designers and animators who work in a wide range of roles at small advertising agencies, visual effects and computer game and film production companies for the contemporary digital media industries, while occasionally engaging in projects on free culture and independent film making.

The material for this study comes from a large research project on the media practices of two free software computer graphics communities: those formed around the programs Blender for 3D animation and Synfig for 2D animation. The data has been collected through multi-sited ethnography and qualitative interviews with 35 visual media artists and developers. They were held between 2013 and 2015 and documented the use of these two programs for, predominantly, open and free cultural production (see Velkova, in press). As the large research project progressed, how- ever, it became clear that the same producers who engage, for payment, in open cultural production and free software development also work in different roles for the media industries where they put the same media production tools to use. Some have worked on large projects such as the LEGO movie or Pixar's short films or for Rovio, who own the Angry Birds franchise. Others work for advertising agencies across Europe, develop animation for educational projects, or create independent and free culture films. Oscillating between two supposedly antagonistic fields of media production, by having a relation to the industries and to free culture projects, the empirical material that underpins this article represents a fruitful starting point to explore the broader value of free software as a media production tool beyond its uses for radical politics.

The approach I take here is to first briefly outline the work context in flexible capitalism using the overarching framework of Boltanski and Chiapello (2007) on the moral justifications that motivate society to engage in the ideology of capitalism. I then apply a narrow focus on digital media production and draw on Howard Becker's work on 'Art Worlds' (1982/2008) in order to discuss the role of materiality in creative practice, which I connect to the conditions of producing media in flexible capitalism.

The argument developed here is that free software for visual media production is conceived by media creators as a form of material capital that represents a source of creative emancipation and security in relation to their creative practice in the highly competitive media production environment. These forms of empowerment, however, are not mobilised to serve a broader critical political project, but represent individual pragmatic strategies to extend digital artists' creative autonomy in the media industries or establish links of equivalence with them while nurturing further precarity.

\section{Media Production and Free Software in the New Spirit of Capitalism}

Digital visual media production takes place today to a large extent in the context of post-Fordist work frameworks that promote 'creativity, reactivity and flexibility' (Boltanski \& Chiapello, 2007, p. 90) as core cultural values. In their seminal work on the transformations of capitalism between 1960 and 1990, Luc Boltanski and Eve Chiapello advance the thesis that these values are not universal but rather manifestations of a new 'spirit' of capitalism. By 'spirit' they refer to a set of normative and moral rules that justify society's engagement in capitalism. These rules need to offer a promise of some form of autonomy and security for individuals while serving the common good. In terms of autonomy, Boltanski and Chiapello argue that there should exist an incentive for people to engage in the process of accumulation even if they will not necessarily enjoy the 
main benefits of it. Individuals also need to feel some form of security for themselves and their children, while participation in accumulation needs to be justified as serving 'the common good which contributes to producing for everyone' (p. 8) and being just.

The transition to post-Fordism in the 1980s and 1990s is regarded by Boltanski and Chiapello as a specific point in capitalism when its justification apparatus is radically redefined. In terms of autonomy, the core values become 'the development of oneself and one's employability' (p. 111). The former emerges through the paradigm of constant improvement of skills, reputation, being adaptable, self-organised, and participate in novel and exciting projects. To become employable, workers need to know how to engage in a project and to remain 'adaptable, physically and intellectually mobile' (p. 112). Enhanced by networked communications, qualities such as flexibility and adaptability are argued to emerge from activity and autonomy, rather than from obedience and belonging to hierarchical structures. In this way, personal development as an option for 'everybody' serves the ideal of the common good, while contributing to broader processes of value production and its accumulation.

This spirit is particularly identifiable in the contemporary media industries and in the debates about autonomy and control of media work. These industries carry a strong allure for young people and creators promising work of greater social status, autonomy, personal expression, flexibility and self-actualisation (Mayer, 2014). To stimulate their employees' creativity, many media companies adopt an anti-corporate work culture and on occasions enable creators to develop a reputation of being an 'auteur' (Deuze, Martin, \& Allen, 2007), a celebrity (Hesmondhalgh, 2009), or a person with broader public recognition (Mayer, 2014). At the same time, the organisational frameworks of production are dependent on constant rationalisation of labour in order to accelerate production and reduce costs, thus constraining the autonomy of creators and adjusting it to market demands. They do so by, first, transferring ever greater responsibility for personal artistic and technical skill development to individual creators and, second, by embedding creators in institutions of employment and regulatory systems of intellectual property that detach creators from their creations, converting their labour into an object of value extraction (Deuze, 2007; Huws, 2014; Stahl, 2010). In the latter context, free software development has been acknowledged to have a potential to bring change in terms of offering more efficient and less alienating ways of organising and managing media production (Benkler, 2006). These alternatives have nonetheless been questioned in terms of their financial viability (Hesmondhalgh \& Baker, 2010) and placed free software in the context of the free labour debates (Terranova, 2004), two issues that I have engaged with and nuanced extensively elsewhere (Velkova \& Jakobsson, 2015).

In the context of digital media production, free la- bour has been discussed largely in terms of the unpaid work that media users perform by producing content in various online contexts, work that is valorised by the media industries (see for example Bolin, 2012; Hesmondhalgh, 2010; van Dijck, 2009). However, unpaid work has always been integral to certain spheres such as those of social reproduction (Jarrett, 2016) or cultural production (Hesmondhalgh, 2010, p. 277). In these spheres, free labour can be regarded not only in terms of paid or unpaid, but also as good and bad, just and unjust (Hesmondhalgh \& Baker, 2010). For example, the internship systems in the media industries today are largely unjust, but unpaid labour as such has always been part of the process of developing skills, ranging from learning to play music instruments to programming, computer graphics and game development (Hesmondhalgh, 2010). Rather than being unjust, the latter forms of free labour stem from the dependency of cultural production on materiality and are addressed in part by Howard Becker (1982/2008) in his work on the sociology of art production. I will discuss this dependency later.

Free software producers are also able to engage in the valorisation of their products (Velkova \& Jakobsson, 2015), something which, as Barron (2013) shows, has transformed it from a critical practice to a distilled form of the 'spirit' of contemporary capitalism. Converting technology into global software commons, free software enables autonomy and project mobility for everyone, serving the common good. What it falls short of, Barron concludes, is to guarantee security to those who engage in its development, thus paving the way for new forms of criticism.

Indeed, security is what Boltanski and Chiapello dismiss as the new 'spirit' of capitalism not offering enough solutions to. The main security that projects or companies can offer to individuals today is development of personal capital that could help employability in future projects and initiatives.

However, as I will argue, free software could represent a specific form of security, that of material security, that enables media creators who engage in using and developing it to also gain a form of creative autonomy, namely craft autonomy. In order to understand how this happens, we need to take a different perspective on free software and approach it as a media production tool rather than a model of organising work. This article therefore continues by exploring more deeply the relationship between technology and digital media creators rather than that between individuals and the broader organisational structures of media production.

\section{Materials for Media Production}

Employability and participation in media projects is largely predicated on the creativity and technical skills of creators, whose practice in turn develops in relation to the materials, or tools, available to them. In the cur- 
rent 'spirit' of flexible capitalism, media creators need to be adaptable and flexible not only in relation to the organisations or projects that they work on; their possibility to sell their work or develop criticism also depends on the flexibility and creative autonomy that the technologies they work with can offer them.

From this perspective, creators of media are not only integrated in structures of employment, nation state politics, or networks of peers, but also in the specific logics of technology with which they interact daily and in which they are embedded at multiple levels. The sociology of art proposed by Howard Becker (1982/ 2008) offers some insights into how to understand these entanglements in relation to creative autonomy. In his discussion of art as collective action, Becker emphasises that creators' choice of materials affects the work they do (p. 71). Materiality forms a crucial part of the production of artistic works:

"Musical instruments, paints and canvas, dancers' shoes and costumes, cameras and film-all these have to be made and made available to the people who use them to produce art works." (Becker, 1982/2008, p. 3)

In the case of producing specialised media, e.g. digital visual media, creators need materials that are designed and manufactured specifically for them. Becker argues that since the manufacturing of specialised items is so technical a specialty, the artists who use them cannot in most cases produce the items themselves. Despite the fact that manufacturers try to be sensitive to the needs of the creators of a particular medium, they may fail to satisfy those who try to innovate in the medium: 'How much conventional materials constrain an artist depends on how monopolistic the market is', he argues (p. 73). Through this argument Becker establishes a link between technical innovation, creative autonomy and the frameworks of creation and distribution of materials. The fewer manufacturers that dominate the market, he argues, the more insensitive they become to what artistic minorities want or need. Occasionally, artistic minorities can revert to the craft of making their own materials, or of customising existing ones if faced with the threat of discontinuing the material against which creators have developed their skill, if they want more than the available materials can provide or if materials to satisfy a creative impulse are not available (Becker, 1982/2008, p. 71ff)

It is in this context, and rather pragmatic considerations about individual strategies to develop creative practice, that free software emerges as a tool of high value among media professionals, digital artists and aspiring media workers. The next section substantiates this point through a discussion of the emergence of two popular free software tools for computer graphics production, Blender and Synfig.

\section{Crafting Technical Autonomy: The Blender and Synfig Free Software Projects}

The free software discussed here, Blender for 3D animation and sculpting and Synfig for 2D vector animation, were conceived as digital tools that would enable their creators to exercise a greater degree of craftsmanship, innovation and autonomy in the medium. They also represent the free software alternatives for professional animation production to programs such as 3D Studio Max, Adobe After Effects, Anime Studio and Maya.

The 3D animation software Blender and the 2D Synfig were initiated by two industrial designers, one living in Europe and the other in the US, who had ambitions to make large-scale independent animation projects of Hollywood class. Despite having notable differences in their focus of specialisation, and being incepted at different points of time, with Blender having its roots in the late 1980s and Synfig in the mid1990s, both were conceived as in-house programs developed within two small commercial animation studios. After facing bankruptcy in the early 2000s, both projects emerged as free software through very particular processes of de-commodification (Velkova \& Jakobsson, 2015).

In the case of Blender, the need to start developing an independent program emerged from the ambition of its creator, Ton Roosendaal, to align with the industrial practices of 3D technological development:

\footnotetext{
"3D is specialist...it is so specialist....any big studio who does animation-or visual effects-they depend for the most of it on their own, in-house software development. They are not going to buy all their applications-and even when they buy some stuff, they want to have the code. Because they can't depend on a software, submit a bug, then wait for two weeks for a bug fix to come in while a thousand people are waiting, right? That's kind of... at that level your IT, your information systems have to be under control...." (Ton Roosendaal, interview, 2014)
}

Blender emerged from its author's desire to have complete control over the development, changes to and possible extensions of a computer program, 'a digital tool' that would enable its creator to adapt it and mould it to his own creative ambitions.

Until the mid-1990s, software for computer graphics development was distributed as an add-on to very expensive hardware that media creators anyway needed to invest in. The computer industry restructured in the late 1990s. With computing power becoming cheaper and more ubiquitous, companies began developing business models around selling, and more recently renting specialised software for computer graphics production. The changes in the politics of distribution of software for computer graphics production 
have been experienced as constraining creativity, experimentation and large-scale projects by small studios and individual digital artists:

"[In the 1990s] the hardware cost money, but once you had it, you could do anything-we were getting CDs with Silicon Graphics code! It was proprietary stuff, but it didn't prevent us from making things with it....Computer graphics is about openness, because you can build on everyone else's developments. Once you get a patent or close it-people find a way around it." (notes from informal conversation with Ton Roosendaal, May 2015)

Hence, the experiences of material constraints to continue experimenting with computer graphics led Blender's creator to find a way round them by relicensing his program as free software as a strategy to retain technological and creative independence and let the program grow by allowing other digital artists to contribute to it:

"open source is about developing your own software. So the best model [to develop computer graphics]....OK, not the best, the Blender open source model is the in-house software model." (Ton Roosendaal, interview, August 2014)

Similar concerns drove the development of Synfig. Its founder Robert Quattlebaum wanted to rationalise one of the most laborious tasks in 2D animation creation, tweening, and adapt the software to his own creative ambitions:

"Our goal was to write a tool that could be used for the production of feature-film quality 2D animation..... In traditional animation, the senior animators use the storyboards to create the keyframes for each shot. The junior animators then use these keyframes as guides for making all of the frames in betweenwhich is called tweening. Tweening is a timeconsuming and labour-intensive (and thus expensive) process. However, it is also rather mechanical. So that was the original idea from day one-the elimination of the tweening process... While Synfig has been used in production, the animators using it had the benefit of having the primary developer sitting behind them. That counts for a lot." (OS News, 2006)

After its de-commodification in the mid-2000s, and conversion into a free software project, Synfig's development was driven forward primarily by one selftaught animator, Konstantin Dmitriev, from the city of Gorno-Altaysk in Southern Siberia, Russia. For him, Synfig, represented a technology that with some further development could fulfil his creative idea of making a large-scale independent feature-length animation film.
In search of style, his work had begun with proprietary programs such as 3D Studio Max but after some time he experienced a limitation in scale: 'the more I complicated a scene, the less controllable it became...', he explained. Facing in this way a constraint to innovate in the medium, instead of trying to adapt his practice to the technical limitations of the tool, he switched to experimenting with free software as a way to adjust technology to the scale of his creative ideas. Initially he tested Blender, an experience which he describes as largely affective:

"What shocked me in Blender the first time I used it was that it had layers...layers existed in many other types of programs at that time, but not in 3D...this was so daring, to do layers in a 3D program, I had never seen such a thing before." (Konstantin, interview, January 2015)

While improving his skills in Blender, Konstantin also specialised in 2D animation in parallel with using proprietary programs until their development frameworks collided with his own work process. The manufacturer of the $2 \mathrm{D}$ animation program Moho discontinued its development under Linux, which had gradually become Konstantin's main platform. The impossibility to use this software as a production tool caused him great anxiety:

"I liked the fact that everything (in Moho) was under my control. But nobody was supporting it...then I realised what dependencies proprietary software was creating. It is not about the cost, it is about the dependency." (Konstantin, interview, November 2014)

Since then he has focused his efforts on studying and developing the free software Synfig, which he integrated at the core of his creative practice, and multiple projects ranging from free-lancing work to education and independent free culture production (Velkova, 2014).

Both Konstantin's and Ton's choices to invest their time in developing Synfig and Blender respectively emerged out of explicitly pragmatic concerns related to the possibilities to create within frameworks of their own making and under their own control. This form of engagement with technology has been referred to, in the contexts of free software development and hacker cultures, as forms of establishing 'craft autonomy' (Coleman, 2016), one that fosters skill and expertise, but also sensibilities similar to pre-industrial, craft-like engagement with technology. The emergence of these two programs for visual media production is also an indication that constraints to creativity imposed by the politics of creation and distribution of media production tools continue to be a topic of high concern even in digital media contexts, and lead to reactions similar to those that have always been historically present in artistic practice (see Becker 1982/2008, pp. 71-77). 
Despite the freedom of creative expression which developing autonomous media production tools granted to their creators, it also constrained their autonomy in new ways. In order to fulfil their ideas they needed to motivate more people to adopt these technologies and contribute to the free software projects in order to let them grow in functionality. Both Blender and Synfig faced the problem that, instead of developing art projects, they needed to develop frameworks to train or convince other people to use these technologies. As Becker (1982/2008, p. 74) points out, when creators go about developing their own materials, they need to spend time in developing their material precursors and knowledge frameworks instead of working on making art. There is no space in this article to discuss in detail the strategies employed in these cases, but for the present argument it is enough to say that Blender succeeded in creating a large user base on a greater scale than Synfig and is today embraced to a greater extent by animators, digital artists and technical artists who use it for a broad range of purposes. Uses range from experimental concept art projects through developing 3D printing models to experiments with novel forms of artistic collaboration; from open culture projects to the production of special effects, games, animation, and simulations for the media industries.

The variety of uses which it finds implies that the public nature of free software represents a source of value and craft autonomy for a broad range of actors and purposes. The next section discusses three main ways in which digital media artists find meaning in these tools and illustrates how they reconcile craft and creative autonomy with efficiency, independence, ultimately securing materially their creativity.

\section{Sensibilities of Craft}

Every media creator has a unique work process. The more creators develop their skill, the stronger the connection established to the tools they use, as this skill is shaped through practice which is anchored in the materialities of technologies, even in the case of digital ones.

French free-lancing illustrator and digital comic artist David Revoy recalls how he used to work with proprietary digital production tools such as Corel Painter, Manga Studio, Photoshop Elements and CS2. After upgrading to a newer computer and a newer version of a proprietary operating system, all these tools stopped working: 'I had to do a lot of horrible hack to make all my software run on it, but it wasn't [as] stable as it was on Xp anymore. I had to reboot almost twice a day' (Revoy, 2013). From a tool that automates and mediates creative expression, media production software can become an artifact with 'agential' (Paasonen, 2015) properties that may, for a time, leave the user powerless. Faced with the choice of either re-purchasing all his programs to match the new operating system and hard- ware, reverting to the older computer and operating system, or doing something completely different, Revoy (2013) chose to move to free software: 'I thought all of this circus couldn't work in the long term and wasn't happy.... I switched my machine to a full open-source system around 2009...thinking opensource could work on the long term.'

The result of this move was not explained in terms of economic gains, but in the qualitative difference related to a new degree of creative autonomy and security gained in relation to technology:

"I really like the independence I get from it: I can install it on laptops, every machine, upgrade, downgrade, fine-tune it. This independence is gold. The con is that I'm now dependent on 'Linux' compatible [hardware]. Which is not easy to find and not well documented." (Revoy, 2013)

If, for David, free software was initially a way to reduce his material and creative dependency from technological frameworks out of his control, for other media producers switching to free software has been a way to increase their work efficiency.

Hjalti, an animator from Iceland who has worked for many years in the advertising industry, encountered Blender by chance after many years of using the popular package 3D Studio Max. He adopted Blender in his practice out of a desire to collaborate on a commercial campaign with a colleague of his who had it as a tool of his choice. He discusses his initial experience of learning Blender as an agony that has been worth it:

"I was throwing my keyboard at the screen for the first couple of weeks or whatever, but once you get over it you start to realise why it makes sense. Why pressing $G$ is already moving an object...instead of like having a widget that you press on...it's because it's faster. It just cuts a lot of steps out of the way. Which adds up. So you start doing things a little faster. And smoother. And then of course you can customise everything you want now after Blender 2.5. Which I do, a lot." (Hjalti, animator, interview, August 2014)

Later versions of Blender and Hjalti becoming more experienced with it allowed him to adapt it to his own work process in a way that increased his working speed. In practice this meant adjusting small details, such as the position of his hands which he wanted to keep static while working. Until moving to Blender, whenever he needed to change perspectives on the screen while animating, the program interface would require him to move his hand to the keypad on the right side of his keyboard. He experienced this as a constraint to be efficient: 
"I am doing it every 10 seconds. And take one second to let go of my mouse, I am losing valuable time, you know, after 15 hours or whatever...and it also breaks your concentration. Because your eye, your thought process has to go into that motion instead of just keeping going, doing what you are supposed to be doing." (Hjalti, animator, interview, August 2014)

After version 2.5 of Blender it was easier for its users to customise their work processes to a great degree. Hjalti used this possibility to assign his own commands in such a way that he would no longer need to move his hands away from the keyboard while working. Such a seemingly minor detail was very important for him as regards experiencing a sense of craft:

"That's when it becomes really beautiful. When the tool itself doesn't become a hurdle, you are just doing something and it's an extension of you....So you can do something, you can adjust something, it's intuitive. It is muscle memory. Which is really awesome." (Hjalti, animator, interview, August 2014)

This example shows how free software as a production tool is conductive to frameworks of rationalising production, and personal skill development while maintaining a strong sense of autonomy among its users. This combination ultimately gives a competitive advantage in the media industries' labour market. Of course, possibilities for customisation exist in other software too yet, in line with Becker's argument about the constraints of materials, the limits to which free software allows creators to adapt technology to their everyday practice depends more on individual technical skill and creative ideas than on the production frameworks and affordances set by software manufacturers.

Besides reducing dependencies and increasing efficiency, many digital artists value free software for its infinite adaptability and extensibility. In the spring of 2014, a free-lancing animator and a technical artist from Costa Rica worked on a 4-second shot for the teaser for a larger free culture animation film project. The shot was supposed to show a green caterpillar blinking. The animator wanted the caterpillar's pupils to resemble the facial features of the main character in the animation film. They were using Blender for this production task and found that it did not have the technical capacity to animate the desired effect. The technical artist came up with a concept for how the problem could be solved and delved into the program code: 'I started hacking a python script to automate this ^_^. At about 3:00am it actually worked!'. He shared the script and the technical details online with the following comment:

"Beware it's a production script and as such it doesn't have a nice UI or anything and you might need to change a couple of names in the first few lines :)." (Salazar, 2014)

In this case, the animation process was very similar to hacking. Hackers, artists and free software developers have come to be described as 'craftspeople' who have resisted the general decline of craft in the Western that came with the dominance of Fordist styles of production (Coleman, 2016).

A common metaphor frequently used among the digital artists who were interviewed was to compare working with free software to the work of painters from pre-industrial craft production: 'It is more like the old painters who made their paint themselves. Mixing the ingredients and building their paint themselves', Timothée Giet, a comic illustrator explained. In these cases, the possibilities to craft and mould their own tools blur the separation between art and craft, techne and poiesis:

"Free software matches very good with the artistic idea because no artist wants to be locked into what they can do-a lot of the process of making art is about making the tools." (Bassam, animation director, archived blog post, 2014)

The above examples illustrate how free software strengthens feelings of creative autonomy in their users by being flexible and adaptable to individual needs for creativity, efficiency and material independence. In their totality, these experiences construct free software as a source of individual material security and capital that allows digital artists to gain competitive creative advantage in the post-Fordist media industry frameworks. With the increased transfer of responsibility over skills development to individual media creators, the choice of technology becomes an investment that can increase media producers' mobility and employability in different projects. At the same time, while free software stimulates a craft-like engagement with technology, it illuminates how the values of personal self-development, flexibility and security of the new 'spirit' of capitalism become embedded in digital artists' technological choices. The problem to which the latter leads is that the security and autonomy that controlling and extending free software digital tools gives may decrease criticism of some problematic aspects of the post-Fordist production frameworks, e.g. precarity of labour. As the next section will show, while digital artists strengthen their creativity and material security through free software, they further nurture precarity of work.

\section{Tools Development as a Source of Precarity}

Once digital artists identify free software as tools of value to them, they employ different strategies to attempt to further shape and adapt the programs to their indi- 
vidual needs. Those artists who are unable to code (and they constitute a majority), or do not want to dedicate time to code, resort to financial and rhetorical means to convince programmers to do the work for them. Below I discuss three dominant ways in which this can happen.

\subsection{Hiring a Developer}

The technical possibility to extend Blender for other purposes than those intended by its original creator emerged from a technical artist's need to rationalise his process of work at a wealthy media production company. He attempted to find a less costly and more flexible alternative to a professional 3D program that could satisfy the production needs of the company: 'I got Blender and I started extending it', he remembers. He admits that his programming skills were not good, so he hired a programmer from Canada to come to Australia to do the extension for him:

“Well, no, I didn't know how to program, like-I was, I was artist, so-I was OK, making stuff with the mouse. But I knew some programmers so I got them to program...I hired them to program. I had one of the Blender developers come over to my house, doing internship with me, so I got him to program so it was like-the artist and developer thing happening." (technical artist, interview, 2014)

The functional extensions made at that time entered the core of Blender and made it possible for other artists to further develop the program. While representing a contribution to the common good, the possibility that free software opens for an artist to hire a developer changes the artist's status. From being a wage-earner who sells his or her work to the industry, the artist can become an employer who creates small, temporary jobs for programmers. By offering programmers temporary projects, digital artists mirror the frameworks of the media industries by outsourcing jobs with the promise of personal development, employability and a wage, for the common good. Hence, while free software represents a source of material security for artists, it becomes a source of work insecurity for developers, further nurturing precarity.

\subsection{Becoming a Financial Patron of a Project}

Another common strategy used by artists to influence the general direction of free software tools development is to become a financial patron of the project. This can happen by making small donations to the free software projects in order to buy developer time to develop the project in the direction they want.

A free-lancing animator from Sweden who specialises in cut-out animation which he sells to the Nordic advertising and film industries explained how he could make small financial donations to Synfig to push its development in the direction he needed. His principle has been to donate 3-4 per cent of his income from commercial projects to the free software projects he uses, with occasional higher donations in order to set a priority for the development of a specific feature. He remembered during a conversation we had how he once paid a few hundred euros to the project to speed up the development of a specific function in Synfig that he needed in his work for the industry.

This form of exercising influence over the broader technical development of the project turns digital artists into patrons who become connecting links between a media project (be it for the industry or not), the creative visions of an artist and the technical community that can be convinced to prioritise the development of a feature.

\subsection{Motivating Developers}

When artists do not have financial means to invest in a project, they resort to rhetorical means to motivate a developer to do the job for them for free, an approach that is the driver of major disputes in the communities formed around free software tools.

Digital artists can request features and extensions directly from the programs' main developers. Mobilising rhetoric and prototypes of unfinished media projects in order to illustrate the need to improve software in a particular direction, these interactions become the locus of many tensions and conflicts. In some cases, feature requests are welcomed and fulfilled, but in most cases they are ignored:

\footnotetext{
"We get far, far more requests than we even have time to read. Also, these requests vary in quality. People may explain features in detail, which we already have....People ask for very specific stuff...'I'm using Blender for an interactive blah blah and it's draw modes don't work for me because...etc'.... People who use Blender for ten minutes and don't like colour also post..." (Blender developer, interview, December 2014)
}

This example illustrates the fact that despite gaining a greater technical autonomy, free software makes digital artists deeply embedded in the social dynamics surrounding the maintenance and development of their tools of choice. Those artists who manage to convince the developers of the importance of their request are usually those who are most active in the media industries and have concrete, urgent needs:

"I was already doing graphics that were watched by millions, and I started falling in love with [Blender] because it is so versatile. And plus I really liked the idea that you could change the program.... That's 
what sold me on Blender. Wasn't the interface, wasn't the toolset, it was just the fact that you could change it. That made the case that even if you are not happy with it, if you argue for your case well, you can actually get changes to it." (Beorn, animator, interview by BlenderGuru.com, 2014)

Hence, a rhetorical approach anchored in a concrete project for the media industries can become the equivalent of a financial donation as its fulfilment may bring value for a broader range of digital artists while satisfying individual creative demands.

\section{Conclusions}

The empirical examples discussed in this article show that free software's role in the politics of digital media production should be understood as individual strategies to find material security and extend personal creative and craft autonomy through technological choices. Approaching free software as a tool, rather than as a form of organising work, allowed the degree to which digital media creators' creative autonomy is configured to be illuminated in relation to the affordances, mouldability and degree of control over the programs that they use in their everyday creative practice. The main issues which artists used to struggle with in the past, as described by Becker (1982/2008), such as dependency on materials and the frameworks of their production, changes in the politics of their distributions, and not least, their affordances, remain highly relevant in the contemporary digital mediascape.

Drawing on Becker, the article conceived free software as a strategy to develop one's own materials and independent frameworks of production in response to changes in the political economy of software distribution. In Becker's framework, such an approach has been commonly used by artistic minorities. This article has shown that free software can resemble this approach by becoming relevant for a broader range of users, beyond creative minorities, in particular those working in different roles for the contemporary media industries. Free software as a source of value for digital artists is thus about meaningful, and not ideological, self-realisation (cf Hesmondhalgh \& Baker, 2010, p. 180ff). In the new 'spirit' of capitalism that promotes self-development and outsources the responsibility for skill development to media producers, the ability to shape technology according to distinct creative ideas becomes an individual strategy to remain flexible and competitive.

The specific ways in which artists find meaning from using free software as a production tool are in bringing their work to a form of pre-industrial craft, and saturating their work with an attitude described by Peter Dormer as: 'you get the best out of the computer and its software if you are able to drive the tool rather than being driven by it' (Dormer, 1997, p. 146). The senses of craft autonomy developed through free software are, importantly, not mobilised for a broader critical or political project for social change, but are rather pragmatic, rooted in strategies to influence technological development in ways that benefit one's individual work practice. As a consequence, digital artists inscribe further the values of the new 'spirit' of capitalism, embedding them in the free software tools that they use and develop.

Finally, in crafting security and autonomy for themselves, digital artists do not offset some of the negative effects of flexible capitalism, such as the shift of responsibility for skill, personal development and finding work onto individual creators. Rather, their practices further nurture precarity of labour by them becoming employers or patrons of other groups of creative workers, such as hackers and software developers. Further research could fruitfully explore the practice of media workers hiring developers to code functionality for them and study whether such engagements create new hierarchies or forms of exclusion, or whether they are a positive source of pleasure from digital work that enhances autonomy and creativity in the digital media industries.

\section{Acknowledgements}

This article has greatly benefitted from the comments and close readings of Patrik Åker, Göran Bolin, Johan Fornäs, Peter Jakobsson and Fredrik Stiernstedt, as well as the two anonymous reviewers. Special thanks go to Paško Bilić and Dina Vozab, the Croatian Sociological Association, as well as the ECREA Doctoral Summer School 2015 for providing me with a platform to develop the first drafts of this contribution.

\section{Conflict of Interests}

The author declares no conflict of interests.

\section{References}

Atton, C. (2007). Alternative media in practice: The Indymedia network. In K. Coyer, T. Dowmunt, \& A. Fountain (Eds.), The alternative media handbook (pp. 71-78). New York: Routledge.

Baack, S. (2015). Datafication and empowerment: How the open data movement re-articulates notions of democracy, participation, and journalism. Big Data \& Society, 2(2).

Barron, A. (2013). Free software production as critical social practice. Economy and Society, 42(4), 597-625.

Becker, H. S. (2008). Art worlds. London: University of California Press. (Original work published 1982)

Benkler, Y. (2006). The wealth of networks how social production transforms markets and freedom. New Haven: Yale University Press.

Bolin, G. (2012). The Labour of media use. Information, Communication \& Society, 15(6), 796-814 
Boltanski, L., \& Chiapello, È. (2007). The new spirit of capitalism. London: Verso.

Coleman, G. (2013). Coding freedom: The ethics and aesthetics of hacking. Princeton: Princeton University Press.

Coleman, G. (2016). Hackers. In B. Peters (Ed.), Keywords: A vocabulary of information society and culture. Princeton: Princeton University Press.

Deuze, M. (2007). Media work. Cambridge: Polity.

Deuze, M., Martin, C. B., \& Allen, C. (2007). The professional identity of gameworkers. Convergence: The International Journal of Research into New Media Technologies, 13(4), 335-353.

Dormer, P. (1997). The culture of craft: Status and future. Manchester: Manchester University Press.

Gehl, R. W. (2015). The case for alternative social media. Social Media + Society, 1(2), 1-12.

Hesmondhalgh, D. (2009). The cultural industries (2nd ed.). Los Angeles: Sage.

Hesmondhalgh, D. (2010). User-generated content, free labour and the cultural industries. Ephemera, 10(3/4), 267-284.

Hesmondhalgh, D., \& Baker, S. (2010). Creative labour: Media work in three cultural industries. Abingdon: Routledge.

Huws, U. (2014). Labor in the global digital economy: The cybertariat comes of age. New York: Monthly Review Press.

Jarrett, K. (2016). Feminism, labour and digital media: The digital housewife. New York: Routledge.

Kelty, C. M. (2008). Two bits: The cultural significance of free software. Durham: Duke University Press.

Kelty, C. M. (2013). There is no free software. Journal of Peer Production, 3. Retrieved from http://peerprodu ction.net/issues/issue-3-free-software-epistemics/de bate/there-is-no-free-software

Kubitschko, S. (2015). Hackers' media practices: Demonstrating and articulating expertise as interlocking arrangements. Convergence: The International Journal of Research into New Media Technologies, 21(3), 388-402.

Lievrouw, L. A. (2011). Alternative and activist new media. Cambridge: Polity.

Mayer, V. (2014). Creative work is still work. Creative Industries Journal. doi:10.1080/ 17510694.2014.892286

Morgan, T. (2013). Sharing, hacking, helping: Towards an understanding of digital aesthetics through a survey of digital art practices in Ireland. Journal of Media Practice, 14(2), 147-160.

OS News. (2006). Interview with Synfig's Robert Quattlebaum. Retrieved from http://www.osnews.com/ story/13241

Paasonen, S. (2015). As networks fail: Affect, technology, and the notion of the user. Television \& New Media, 16(8), 701-716.

Revoy, D. (2013, May 1). Why I use open-source? Retrieved from http://www.davidrevoy.com/article 170/the-choice-of-open-source

Salazar, D. (2014). Caterpillar making of-Animating UVs. Retrieved from https://gooseberry.blender.org/ caterpillar-making-of-animating-uvs

Söderberg, J. (2011). Free software to open hardware: Critical theory on the frontiers of hacking (Doctoral dissertation). Gothenburg: University of Gothenburg.

Söderberg, J. (2014). The cunning of instrumental reason: Reproducing wealth without money one 3D printer at a time. In J. Söderberg \& S. Maxigas (Eds.), Book of peer production (pp. 46-58). Gothenburg and Århus: NSU Press.

Stahl, M. (2010). Cultural labor's 'democratic deficits': Employment, autonomy and alienation in US film animation. Journal for Cultural Research, 14(3), $271-$ 293.

Terranova, T. (2004). Network culture: Politics for the information age. London and Ann Arbor: Pluto Press.

van Dijck, J. (2009). Users like you? Theorizing agency in user-generated content. Media, Culture \& Society, 31(1), 41-58.

Velkova J. (2014). Two weeks in Siberia with Morevna Project, open-source animation tools, and Animé. Retrieved from http://phd.nordkonst.org/?p=84

Velkova, J. (in press). Ethnography of open cultural production: From participant observation to multi-sited participatory communication. In N. Wildermuth \& T. Ngomba (Eds.), Methodological reflections on researching communication and/for social change. London: Palgrave Macmillan.

Velkova, J., \& Jakobsson P. (2015). At the intersection of commons and market: Negotiations of value in opensourced cultural production. International Journal of Cultural Studies, August, 1-17.

\section{About the Author}

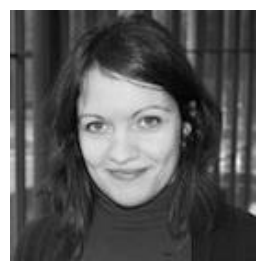

Julia Velkova is a PhD candidate in Media and Communication Studies at Södertörn University in Stockholm, Sweden. In her dissertation project she explores forms of autonomy, value creation and power enacted within techno-artistic practices that are centred on building independent media production infrastructures and content. Her broader research interests are on computer cultures, the politics of infrastructure and internet governance. 